\title{
Magnifying advanced endoscopy in collagenous colitis: now you see?
}

\section{(ㄷ)(우우}

\author{
Authors \\ Anastasios Koulaouzidis ${ }^{*}, 1$, Ervin Toth ${ }^{*}, 2$ \\ Institutions \\ 1 Endoscopy Unit, The Royal Infirmary of Edinburgh, \\ Edinburgh, United Kingdom \\ 2 Endoscopy Unit, Skåne University Hospital, Lund \\ University, Malmö, Sweden \\ Bibliography \\ DOI https://doi.org/10.1055/s-0043-118412 | \\ Endoscopy International Open 2017; 05: E1074-E1075 \\ (c) Georg Thieme Verlag KG Stuttgart · New York \\ ISSN 2364-3722
}

\author{
Corresponding author \\ Anastasios Koulaouzidis, MD, Endoscopy Unit, The Royal \\ Infirmary of Edinburgh, 51 Little France Crescent, \\ Edinburgh EH164SA, United Kingdom \\ Fax: +44-131-2421619 \\ akoulaouzidis@hotmail.com
}

Microscopic colitis is an umbrella term used to describe two distinct entities - collagenous colitis and lymphocytic colitis [1]. The syndrome of microscopic colitis presents with chronic, nonbloody, watery, and often severely debilitating diarrhea. Histological examination remains the reference standard for microscopic colitis diagnosis. However, the term "microscopic" has been hotly debated over the years, with an increasing number of publications confirming that the initial proposal of "microscopic colitis" as a defining term comes from the early days of the collagenous colitis/lymphocytic colitis syndrome diagnosis, when neither advanced endoscopic imaging nor the combination of modalities during endoscopy were readily or widely available [2,3].

Early reports, using standard white-light imaging and indigo carmine dye spraying chromoendoscopy, had indicated the presence of abnormal vascular and surface patterns [4]. Recently, nonspecific and subjective findings, to an extent dependent upon the endoscopists' experience [5,6], such as patchy mucosal erythema and/or mucosal edema, and abnormal vascular pattern, can be seen with standard-definition endoscopy in up to $30 \%$ of patients [5]. Nevertheless, the specificity of the aforementioned findings and others such as cat scratch colon (i.e. bright red linear markings at the right side of the largebowel mucosa) is as low as $14 \%[7,8]$. That really only leaves acute mucosal lacerations or mucosal fractures (as described by some) as almost pathognomic for collagenous colitis, and these findings have been associated mainly with the use of proton pump inhibitors such as lansoprazole [3].

\footnotetext{
* Both authors contributed equally to this paper.
}

It therefore comes as no surprise that the other unresolved issue in collagenous colitis is the correlation of the location (as well as the severity) of the endoscopic findings with that of mucosal inflammation and more specifically the thickness of the collagenous band. It has been suggested that the presence of a thick subepithelial collagen layer (i. e. $>10 \mu \mathrm{m}$ ) makes the colon stiff and the mucosal layer easier to dehisce and fragment [9].

Recently, we presented a detailed case series on collagenous colitis [2], and we proposed that the time has come to acknowledge the rise in the incidence of endoscopic findings in "microscopic colitis" and, more specifically, in collagenous colitis. We believe that increases in the reporting of endoscopic findings can be attributed to an improvement of endoscopic equipment and an increased awareness of the entities of collagenous colitis and lymphocytic colitis among colleagues, as well as the application of advanced endoscopic imaging, such as chromoendoscopy (digital or with application of dye), high definition endoscopy or confocal endomicroscopy $[4,8,10,11]$.

To this effect, the presentation of one more case series by Kobayashi et al. [12], in this issue of Endoscopy International Open, adds further ground to our claim. In this study, the authors re-endoscoped five consecutive patients with biopsy-confirmed collagenous colitis. Four out of the five cases were men and all were treated with lansoprazole to prevent aspirin-related gastroduodenal ulceration. Interestingly, in all cases, complete resolution of clinical symptoms of collagenous colitis was achieved within a month by stopping proton pump inhibitors. Another 12 asymptomatic individuals who were also on lansoprazole for treatment of reflux esophagitis or for prophylaxis 
against nonsteroidal anti-inflammatory drug-induced ulceration, were evaluated as the control group in the study.

A magnifying video endoscope CF-HQ290ZI of the Lucera Elite spectrum (Olympus Corp., Tokyo, Japan) was used to perform the colonoscopies. Magnifying endoscopy was used to observe white-light images, narrow-band images (NBI), and indigo carmine spraying ( $0.5 \%)$. To the best of our knowledge, this is the first time that all of the above modalities have been applied in combination, albeit in a limited number of cases. Biopsies were performed not only in abnormal-looking colon areas, but as a standard one-sample per colonic segment as well.

In essence, in a clever manner the investigators applied the best possible diagnostic techniques/modalities for each of the individual findings suggestive of collagenous colitis: pathology of the subepithelial capillary network was examined by magnifying NBI; presence or absence of mucosal edema was examined by indigo carmine dye spraying and magnifying endoscopy. The latter revealed a whitish and clouded honeycomblike appearance at the orifice of the mucosal crypts, whereas the former showed an irregular-caliber submucosal capillary network. In the long path of attempts to correlate endoscopic findings with the presence of subepithelial collagen and essentially that of collagenous colitis diagnosis, the study comes once again to support our long-held belief that the so-called microscopic colitis does not lack macroscopic findings.

We should mention the limitations to this work. First of all, this was a single-center study in a limited number of patients who had already been diagnosed with collagenous colitis. Moreover, the application of magnification endoscopy is not something that is applied in routine clinical practice, unlike the use of NBI. Finally, for a tool to become widely used and available, it has to overcome the time constraints that typically exist in busy, high-volume and fast-turnaround endoscopy units. Thus, a "multimodal" approach such as the one proposed by Kobayashi et al. is time-consuming and possibly still operatordependent.

The quality of the images improves with the technology of the endoscope, allowing for fast and clear recommendation following visualization of the surface and vascular patterns of the colonic mucosa. It takes only a matter of time to confirm the type and specificity of each of the endoscopic findings, thus allowing not only a more accurate diagnosis based on histopathological examination of biopsy specimens, but more immediate initiation of treatment when certain macroscopic findings are present. The latter should be considered especially benefi- cial in high-volume centers, which normally treat biopsies of endoscopic specimens from non-neoplastic conditions with a lesser degree of urgency, thus disadvantaging patients with microscopic colitis from more prompt initiation of therapy.

\section{Competing interests}

None

\section{References}

[1] Münch A, Aust D, Bohr J et al. European Microscopic Colitis Group (EMCG) Microscopic colitis: current status, present and future challenges: statements of the European Microscopic Colitis Group. J Crohns Colitis 2012; 6: 932 - 945

[2] Yung DE, Koulaouzidis A, Fineron P et al. Microscopic colitis: a misnomer for a clearly defined entity? Endoscopy 2015; 47: 754-757

[3] Koulaouzidis A, Saeed AA. Distinct colonoscopy findings of microscopic colitis: not so microscopic after all? World J Gastroenterol 2011; 17: 4157-4165

[4] Sato S, Benoni C, Tóth E et al. Chromoendoscopic appearance of collagenous colitis - a case report using indigo carmine. Endoscopy 1998; 30: $580-81$

[5] Koulaouzidis A, Yung DE, Nemeth A et al. Macroscopic findings in collagenous colitis: a multi-center, retrospective, observational cohort study. Ann Gastroenterol 2017; 30: 309-314

[6] Andrews CN, Beck PL, Wilsack L et al. Evaluation of endoscopist and pathologist factors affecting the incidence of microscopic colitis. Can J Gastroenterol 2012; 26: 515-520

[7] McDonnell WM, Loura F, Pointon MJ et al. Cat scratch colon. Endoscopy 2007; 39: $459-461$

[8] Suzuki G, Mellander MR, Suzuki A et al. Usefulness of colonoscopic examination with indigo carmine in diagnosing microscopic colitis. Endoscopy 2011; 43: 1100-1104

[9] Madalinski M, Koulaouzidis A. Collagenous colitis with mucosal tears in two proton pump inhibitors and non-steroidal naive patients who developed metachronous cancer. J Dig Dis 2013; 14: 51- 53

[10] Cimmino DG, Mella JM, Pereyra L et al. A colorectal mosaic pattern might be an endoscopic feature of collagenous colitis. J Crohns Colitis 2010; 4: 139-143

[11] Kiesslich R, Goetz M, Neurath MF. Virtual histology. Best Pract Res Clin Gastroenterol 2008; 22: 883-897

[12] Kobayashi M, Hoshi T, Morita S et al. Magnifying image-enhanced endoscopy for collagenous colitis. Endosc Int Open 2017; 05: 10691073 